OPEN ACCESS

Edited by: Jeff Sakamoto, University of Michigan, USA

Reviewed by: Mehmet Kadri Aydinol, Middle East Technical University, Turkey

Timothy Sean Arthur, Toyota Research Institute of North America, USA

*Correspondence: Kazunori Takada takada.kazunori@nims.go.jp

Specialty section: This article was submitted to Energy Storage, a section of the journal Frontiers in Energy Research

Received: 01 February 2016 Accepted: 14 March 2016 Published: 30 March 2016

Citation:

Takada K and Ohno T (2016) Experimental and Computational Approaches to Interfacial Resistance

in Solid-State Batteries.

Front. Energy Res. 4:10 doi: 10.3389/fenrg.2016.00010

\section{Experimental and Computational Approaches to Interfacial Resistance in Solid-State Batteries}

\author{
Kazunori Takada ${ }^{1,2 *}$ and Takahisa Ohno ${ }^{2,3}$ \\ ${ }^{1}$ Battery Materials Unit, National Institute for Materials Science, Tsukuba, Japan, ${ }^{2}$ Global Research Center for Environment \\ and Energy Based on Nanomaterials Science, National Institute for Materials Science, Tsukuba, Japan, ${ }^{3}$ Computational \\ Materials Science Unit, National Institute for Materials Science, Tsukuba, Japan
}

Solid-state batteries with inorganic solid electrolytes are expected to be an efficient solution to the issues of current lithium-ion batteries that are originated from their organic-solvent electrolytes. Although solid-state batteries had been suffering from low rate capability due to low ionic conductivities of solid electrolytes, some sulfide solid electrolytes exhibiting high ionic conductivity of the order of $10^{-2} \mathrm{~S} \mathrm{~cm}^{-1}$ have been recently developed. Since the conductivity is comparable to or even higher than that of liquid electrolytes, when taking the transport number of unity into account, ion transport in solid electrolytes has ceased from rate determination; however, it has been replaced by that across interfaces. The sulfide electrolytes show high interfacial resistance to the high-voltage cathodes. Our previous studies have demonstrated that oxide solid electrolytes interposed at the interface reduce the resistance, and they also suggest that the high resistance is attributable to a lithium-depleted layer formed at the interface. This study employs the first-principles calculation in order to gain insight into the interface. The interface structure between an oxide cathode/sulfide electrolyte simulated by the first-principles molecular dynamics has disclosed the presence of lithium-depleted layer at the interface, and the electronic structure calculated on the basis of density functional theory strongly suggests that the charge current preferentially removes lithium ions from the sulfide electrolyte side of the interface to deplete the lithium ion there. These calculation results are consistent with the transport mechanism proposed from the experimental results.

Keywords: nanoionics, space-charge layer, electrode/electrolyte interface, solid-state battery, solid electrolyte, first-principles calculation

\section{INTRODUCTION}

Lithium-ion batteries predominate in today's rechargeable battery systems because of their high energy densities. They have been used portable electronics devices including cellular phones and notebook PC's and serving as a key component in this information society for more than 20 years. Moreover, they start to be installed in vehicles and smart grids for realizing a low-carbon society; however, some issues including safety originating from the thermal and electrochemical instability of their organic-solvent electrolytes have not gone out completely. Because inorganic solid electrolytes exhibit higher thermal and electrochemical stability, use of the solid electrolytes is expected to be 
an efficient solution (Tarascon and Armand, 2001), even if the electrochemical stability is attributed to the kinetic stabilization as suggested in Zhu et al. (2015). However, solid-state lithium batteries had been suffering from low power densities.

Essential materials to improve the power densities are, of course, solid electrolytes with high ionic conductivities. Since ions generally diffuse faster in liquids than in solids, the use of solid electrolytes lowers the power densities. However, high ionic conductivities that are comparable to that in liquid systems have been achieved among sulfide solid electrolytes. Sulfide ions are larger in size and higher in polarizability than oxide counterparts. The large ionic radius leaves wide opening for ionic conduction, and the higher polarizability weakens attraction between lithium and sulfide ions to make the lithium ions mobile (Zheng et al., 2003). Therefore, high ionic conductivities have been often observed in sulfides, as reviewed in Minami et al. (2006) and Takada (2013b), and the highest conductivities in sulfide electrolyte systems have recently reached $10^{-2} \mathrm{~S} \mathrm{~cm}^{-1}$ (Kamaya et al., 2011; Seino et al., 2014).

In addition, sulfide solid electrolytes exhibit high processability. They are relatively soft materials (Sakuda et al., 2013) and show low grain boundary resistance only by compression. Therefore, sintering process is not essential to connect the particles, whereas high temperature sintering is inevitable to connect ionic conduction between particles in oxide solid electrolytes, for instance. Besides the high ionic conductivity, this feature is beneficial for developing solid-state batteries, because high temperature sintering promotes mutual diffusion that forms impurity phases at the interface. However, even such solid electrolytes had not improve the power density to be high enough for practical application by themselves.

As reported in Takada et al. (2008), when a sulfide electrolyte is combined with graphite and $\mathrm{LiCoO}_{2}$, which are typical anode and cathode materials, respectively, to assemble a lithium-iontype solid-state battery, high resistance is found in its cathode. Because the resistance is the highest in the battery to be ratedetermining in the battery reaction, power density will not be improved without reducing the cathode resistance. Ohta et al. (2006) integrates a novel interface structure between the sulfide electrolyte and $\mathrm{LiCoO}_{2}$ into the cathode in order to improve the power density to a practical level. In the interface structure, surface of the $\mathrm{LiCoO}_{2}$ particles is coated with $\mathrm{Li}_{4} \mathrm{Ti}_{5} \mathrm{O}_{12}$, which act as an oxide solid electrolyte on the surface. This surface coating has reduced the cathode resistance by $1 / 20$ and increased the power density to be as high as that of commercial lithium-ion batteries with liquid electrolytes. The interface is designed on the basis of "nanoionics" (Maier, 1995).

Ionic conductors often exhibit anomalous ionic conduction at their surface or interface. It is explained that the anomalous ionic conduction is induced by the changing concentration of mobile ions to form space-charge layers at the interface. Nanoionics has been often reported as enhanced ionic conduction at interfaces, as reviewed in Maier (2014). On the other hand, Takada (2013a) suggests that the space-charge layer appears as a lithium-depleted layer at the cathode interface in solid-state batteries with sulfide electrolytes. Noble potential of the cathode material depletes lithium ions of the sulfide electrolyte at the interface to the cathode material and makes the interface highly resistive. The surface coating, which interposes the oxide electrolyte between the high-voltage cathode and sulfide electrolyte materials, suppresses the lithium depletion to reduce the interfacial resistance.

Although the changes in the electrode properties upon the surface coating are well explainable by the interface model based on nanoionics, origin of the high interfacial resistance and its reduction are still under debate, because changes in the interfacial structure upon the coating, which are predicted by the interface model, have not been visualized yet. Since the space-charge layer lies between solids with only several nanometers in thickness, it has never shown up even on advanced analyses. This study employs computational science using the first-principle calculations in order to get a clear picture of the interfacial phenomena. Results from density functional theory (DFT) calculation for the interfaces to $\mathrm{Li}_{1-x} \mathrm{FePO}_{4}$ cathode materials are combined with experimental results from the interfaces to $\mathrm{Li}_{1-x} \mathrm{CoO}_{2}$ and $\mathrm{Li}_{1-x} \mathrm{Mn}_{2} \mathrm{O}_{4}$ in Ohta et al. (2007) and Takada et al. (2012) to reveal the validity of the space-charge layer model.

\section{MATERIALS AND METHODS}

\subsection{Experiments}

The materials presented in this paper have been already reported in Ohta et al. (2007) and Takada et al. (2012). Thin layer of $\mathrm{LiNbO}_{3}$ was formed on the particle surface of $\mathrm{LiCoO}_{2}$ and $\mathrm{LiMn}_{2} \mathrm{O}_{4}$ from an ethanol solution of alkoxides of $\mathrm{Li}$ and $\mathrm{Nb}$ by a rolling fluidized coating method. The $\mathrm{LiCoO}_{2}$ and $\mathrm{LiMn}_{2} \mathrm{O}_{4}$ powders are commercially available (D10 and M811, respectively; Toda Kogyo). Average particle size and Brunauer-Emmett-Teller (BET) surface area of the $\mathrm{LiCoO}_{2}$ powder are $11.2 \mu \mathrm{m}$ and $0.26 \mathrm{~m}^{2} \mathrm{~g}^{-1}$, respectively, while those of the $\mathrm{LiMn}_{2} \mathrm{O}_{4}$ powder are $5 \mu \mathrm{m}$ and $0.40 \mathrm{~m}^{2} \mathrm{~g}^{-1}$, respectively. Alkoxides used to form $\mathrm{LiNbO}_{3}$ layer are lithium ethoxide and niobium pentaethoxide. The amount of $\mathrm{LiNbO}_{3}$ coated on the surface varies from 0 (uncoated) to $94 \mathrm{mg} \mathrm{m}^{-2}$. The maximum amount corresponds to $\mathrm{LiNbO}_{3}$ layer of $20 \mathrm{~nm}$ in thickness, if the surface of active material particles is uniformly covered with the $\mathrm{LiNbO}_{3}$.

The sulfide solid electrolyte to make the interface to the cathode materials in this study is $\mathrm{Li}_{3.25} \mathrm{Ge}_{0.25} \mathrm{P}_{0.75} \mathrm{~S}_{4}$ (Kanno and Murayama, 2001). It is mixed with the $\mathrm{LiCoO}_{2}$ and the $\mathrm{LiMn}_{2} \mathrm{O}_{4}$ at weight ratios of 3:7 and 1:1, respectively, to form the interfaces in the composite electrodes. Solid-state cells for the electrochemical measurements are assembled from the mixtures $(12.7 \mathrm{mg}$ for the $\mathrm{LiCoO}_{2}$ and $15 \mathrm{mg}$ for the $\mathrm{LiMn}_{2} \mathrm{O}_{4}$ ) as the working electrodes, In- $\mathrm{Li}$ alloy as the counter electrodes and $\mathrm{Li}_{3.25} \mathrm{Ge}_{0.25} \mathrm{P}_{0.75} \mathrm{~S}_{4}$ as the separators. Because electrode potential of the In-Li electrode is $0.62 \mathrm{~V}$ vs. $\mathrm{Li}^{+} / \mathrm{Li}$, cell voltage is presented by adding $0.62 \mathrm{~V}$ in this paper as if the electrode properties were investigated in electrochemical cells with lithium metal anodes. The $\mathrm{LiCoO}_{2}$ cathodes are charged to $4.2 \mathrm{~V}$ vs. $\mathrm{Li}^{+} / \mathrm{Li}$, that is, $3.58 \mathrm{~V}$ in the cell voltage at a constant current of $127.4 \mu \mathrm{A} \mathrm{cm}{ }^{-2}$, while the $\mathrm{LiMn}_{2} \mathrm{O}_{4}$ are charged to $4.3 \mathrm{~V}$ vs. $\mathrm{Li}^{+} / \mathrm{Li}$ at $20 \mu \mathrm{A} \mathrm{cm}{ }^{-2}$, before the electrochemical impedance spectroscopy to evaluate the electrode impedance. 


\subsection{Computations}

The cathode material used in the computations is $\mathrm{LiFePO}_{4} \cdot \mathrm{Li}_{3} \mathrm{PO}_{4}$ and $\mathrm{Li}_{3} \mathrm{PS}_{4}$ are selected as oxide and sulfide-based solid electrolytes, respectively, in order to compare cathode/oxide electrolyte and cathode/sulfide electrolyte interfaces. The $\mathrm{LiFePO}_{4} / \mathrm{Li}_{3} \mathrm{PO}_{4}$ interface is constructed between $\mathrm{LiFePO}_{4}(010)$ and $\gamma-\mathrm{Li}_{3} \mathrm{PO}_{4}$ (100) planes by the computation method reported in Sumita et al. (2015) and Sumita et al. (2016).

On the other hand, because lattice mismatch between $\mathrm{LiFePO}_{4}$ and $\mathrm{Li}_{3} \mathrm{PS}_{4}$ is too large to form a coherent interface, $\mathrm{Li}_{3} \mathrm{PS}_{4}$ is amorphized on the $\mathrm{LiFePO}_{4}(010)$ plane by first principles molecular dynamics simulation (FP-MD) to form the interface as follows. The amorphous $\mathrm{Li}_{3} \mathrm{PS}_{4}$ is constructed from $16 \mathrm{Li}_{3} \mathrm{PS}_{4}$ units stacked on (010) plane of a $1 \times 3 \times 2$ supercell of $\mathrm{LiFePO}_{4}$. The interface is stabilized by FP-MF calculation with a constant-temperature, constant-pressure (NPT) ensemble at the temperature of $400 \mathrm{~K}$, and the pressure of 1.0 atom with the valuable cell dimension perpendicular to the interface. The interface structure is equilibrated under the temperature control by canonical sampling through velocity rescaling thermostat (Bussi et al., 2007) for 40 ps.

In this study, cathode interfacial structures during the cell operation are also investigated. Fully charged $\mathrm{LiFePO}_{4}$, i.e., FePO , is stacked onto $\mathrm{Li}_{3} \mathrm{PO}_{4}$ and $\mathrm{Li}_{3} \mathrm{PS}_{4}$, respectively, and the interface structures are relaxed by FP-MD simulations with an NPT ensemble at $400 \mathrm{~K}$ under 1.0 atom for ca. 200 ps. These interfaces are connected to lithium metal in order to calculate energies relative to its Fermi level.

Computational analyses for these interfaces are according with the procedures in Sumita et al. (2015) and Sumita et al. (2016). Total energies are calculated at the $\Gamma$ point in the super cell approach within DFT implemented in CP2K at www.cp2k. org. The Goedecker, Teter, and Hutter (GTH) pseudopotentials are selected for PBE functional (Perdew et al., 1996) with the local spin density approximation in this study. Valence pseudowave functions are expanded in Gaussian-type orbitals, and the density is represented in a plane wave auxiliary basis in the hybrid Gaussian (MOLOPT DZVP) and plane-wave (240 Ry for cutoff energy) basis set. The $+U$ strategy is applied to include the electronic correlation within the $d$ orbital of Fe, in which the effective $U$ is set to $4.3 \mathrm{eV}$ as in Wang et al. (2007).

\section{RESULTS}

\subsection{Changes in the Electrode Properties upon the $\mathrm{LiNbO}_{3}$ Coating in the Experiments}

The surface coating reduces the cathode impedance, as demonstrated in Figure 1. Each Nyquist plot consists of an arc followed by a tail in the low frequency region. The impedance at the high frequency limit agrees with the resistance of the solid electrolyte layer calculated from the cross section and the thickness of the electrolyte layer and the ionic conductivity of the solid electrolyte. It is, in general, very difficult to derive intrinsic interfacial resistance from impedance data of composite electrodes; however, it is clear that the surface coating decreases the interfacial resistance. The impedance including the interfacial resistance, which draws an arc in the Nyquist plot, is decreased from 670 to $10 \Omega \mathrm{cm}^{2}$ for the $\mathrm{Li}_{1-x} \mathrm{CoO}_{2}$ cathode and from 8000 to $150 \Omega \mathrm{cm}^{2}$ for the $\mathrm{Li}_{1-x} \mathrm{Mn}_{2} \mathrm{O}_{4}$ cathode, that is, by almost two orders of magnitude.

The surface coating has another effect on the electrode properties. Lithium ions are deintercalated from $\mathrm{LiCoO}_{2}$ and $\mathrm{LiMn}_{2} \mathrm{O}_{4}$ in potential plateaus at $4 \mathrm{Vvs}$. $\mathrm{Li}^{+} / \mathrm{Li}$. However, they exhibit additional potential slopes prior to the $4 \mathrm{~V}$ plateaus in the sulfide solid electrolyte during the charging, as shown in the top panels of Figure 2. The surface coating changes the length of the slopes. Before surface coating, both of the $\mathrm{LiCoO}_{2}$ and $\mathrm{LiMn}_{2} \mathrm{O}_{4}$ show potential slopes with almost the same length of $0.2 \mu \mathrm{Ah} \mathrm{cm}^{-2}$. The increasing amount of $\mathrm{LiNbO}_{3}$ gradually shortens the potential slopes, and the slopes finally disappear at the $\mathrm{LiNbO}_{3}$ amount of $94 \mathrm{mg} \mathrm{m}^{-2}$.

The capacities in the potential slopes are very small. For example, the capacity of $0.2 \mu \mathrm{Ah} \mathrm{cm}^{-2}$ based on the BET surface area corresponds only to $0.5 \mathrm{mAh} \mathrm{g}^{-1}$ for the $\mathrm{LiCoO}_{2}$ and $0.8 \mathrm{mAh} \mathrm{g}^{-1}$ for the $\mathrm{LiMn}_{2} \mathrm{O}_{4}$. However, the slopes are not artifact. They appear both in $\mathrm{LiCoO}_{2}$ and $\mathrm{LiMn}_{2} \mathrm{O}_{4}$ with almost the same capacity based on the BET surface areas of the materials and fade to the same degree with increasing amounts of $\mathrm{LiNbO}_{3}$.

\subsection{Electronic and Interface Structures Obtained from the Computations}

Figure 3 plots density of states (DOS) in $\mathrm{LiFePO}_{4}, \mathrm{Li}_{3} \mathrm{PO}_{4}$, and $\mathrm{Li}_{3} \mathrm{PS}_{4}$ against energy relative to Fermi level of lithium metal. They are semiconductors with band gap energies of 3.7, 5.9, and $2.4 \mathrm{eV}$, respectively. The valence band maximum (VBM) of the $\mathrm{LiFePO}_{4}$, which mainly consists of $\mathrm{Fe} 3 d$ orbital, is located at $-3.5 \mathrm{~V}$, indicating that charge reaction of $\mathrm{LiFePO}_{4}$ extracts electrons from the $3 d$ orbitals at $3.5 \mathrm{~V}$ to give the electromotive force in a $\mathrm{Li} / \mathrm{Li}_{1-x} \mathrm{FeO}_{4}$ cell. The VBM's in $\mathrm{Li}_{3} \mathrm{PO}_{4}$, and $\mathrm{Li}_{3} \mathrm{PS}_{4}$, where contribution of $\mathrm{O} 2 p$ and $\mathrm{S} 3 p$ orbitals is predominant, are located at -4.0 and $-2.0 \mathrm{~V}$, respectively.

Figures $4 \mathrm{~B}$ and $5 \mathrm{~B}$ show the crystallographic structures of the interfaces during the cell operation, which are computed by relaxing $\mathrm{FePO}_{4} / \mathrm{Li}_{3} \mathrm{PO}_{4}$ and $\mathrm{FePO}_{4} / \mathrm{Li}_{3} \mathrm{PS}_{4}$ stacks displayed in Figures $\mathbf{4 A}$ and $\mathbf{5 A}$, respectively, by the FP-MD. It shows a clear difference between the interfaces. The structure relaxation leads to little change in the $\mathrm{FePO}_{4} / \mathrm{Li}_{3} \mathrm{PO}_{4}$ interface, while it transfers a significant amount of lithium ions residing in the interface region of $\mathrm{Li}_{3} \mathrm{PS}_{4}$ to the $\mathrm{FePO}_{4}$. As a result, $\mathrm{FePO}_{4}$ has become $\mathrm{Li}_{1-x} \mathrm{FePO}_{4}$. At the same time, the interface region of the $\mathrm{Li}_{3} \mathrm{PS}_{4}$ becomes low in the lithium-ion concentration, while that in the bulk region is not changed significantly, as can be seen in Figure 5B.

\section{DISCUSSION}

\subsection{Formation of Lithium-Depleted Layer at Cathode/Sulfide Solid Electrolyte Interface}

Origin of the high interface resistance at oxide cathodes/sulfide electrolytes can be found in Figure 5B. The FP-MD, which leads the interface to the equilibrium, transfers lithium ions from $\mathrm{Li}_{3} \mathrm{PS}_{4}$ to $\mathrm{FePO}_{4}$ and depletes lithium ions on the $\mathrm{Li}_{3} \mathrm{PS}_{4}$ side of the interface. This result reveals that the space-charge layer appears as a lithium-depleted layer at the $\mathrm{Li}_{1-x} \mathrm{FePO}_{4} / \mathrm{Li}_{3} \mathrm{PS}_{4}$ interface, which should make the interface highly resistive owing to the absence of charge-carrying lithium ions. 

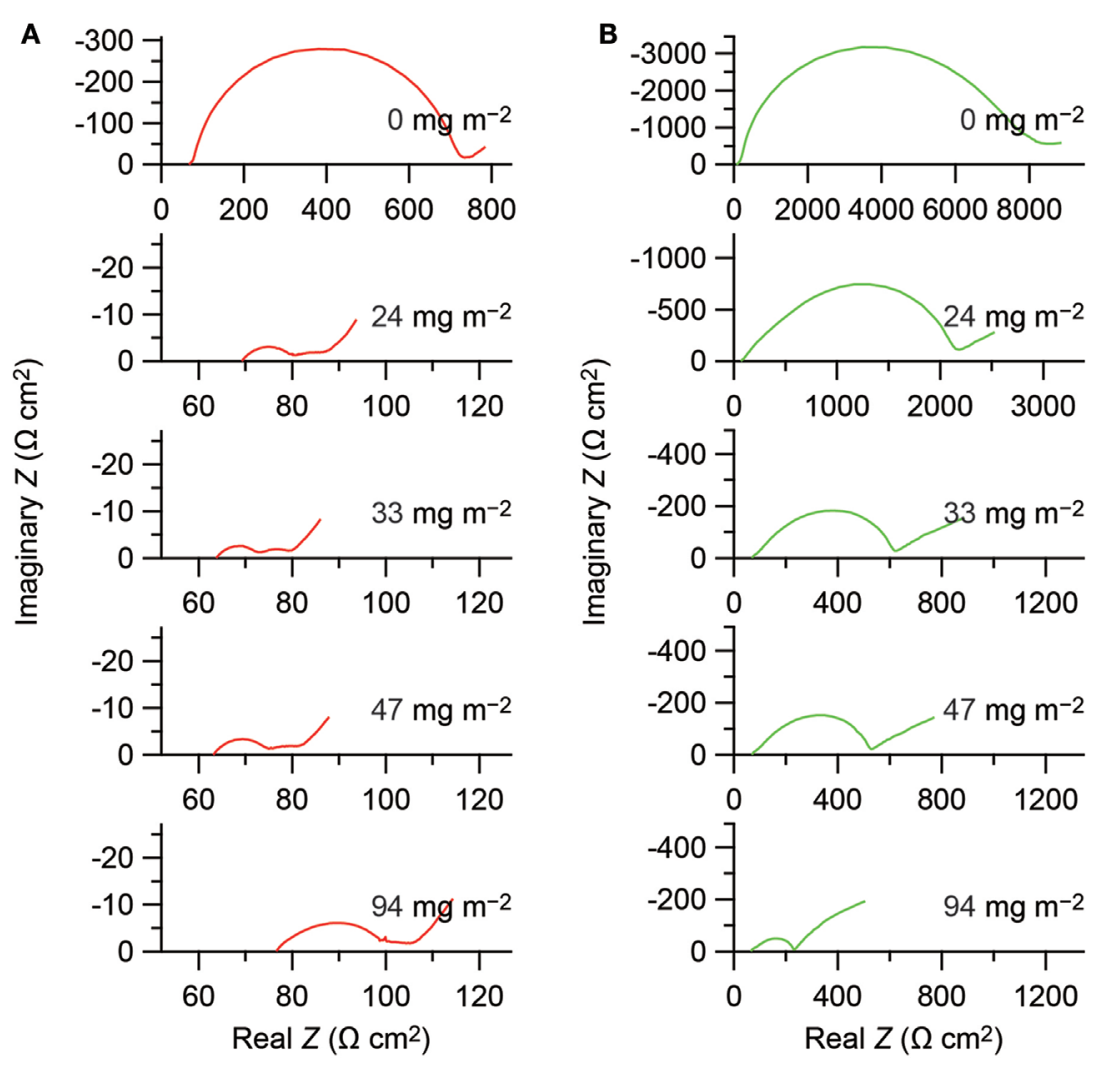

FIGURE 1 | Nyquist plots obtained from the solid-state electrochemical cells with configuration of In- $\mathrm{Li}_{x} / \mathrm{Li}_{1-x} \mathrm{CoO}_{2}(\mathrm{~A})$ and In- $\mathrm{Li}_{x} / \mathrm{Li}_{1-x} \mathrm{Mn}_{2} \mathrm{O}_{4}(\mathrm{~B})$. Horizontal and vertical axes indicate real and imaginary parts of the complex impedance based on the projection areas of the cathodes, respectively. The amounts of the $\mathrm{LiNbO}_{3}$ coating on the active materials are indicated on the basis of the BET surface areas of the active materials in the figures. Impedance date reported in Ohta et al. (2007) and Takada et al. (2012) are replotted in this figure, copyright @ 2007 and 2012, with permission from Elsevier.

This computational results demonstrate that the ion concentration on the electrode surface will be a critical factor governing the interfacial resistance. It is needless to mention that the ion concentration is related to the electrode potential through a Nernst equation.

$$
E=E^{0}+\frac{R T}{z F} \ln \frac{a_{\mathrm{Ox}}}{a_{\mathrm{Red}}}
$$

In the Nernst equation, electrode potential, $E$ is connected to activities of oxidant and reductant, $a_{\mathrm{Ox}}$ and $a_{\text {Red }}$, respectively, with the standard electrode potential, $E^{0}$; the gas constant, $R$; the absolute temperature, $T$; the number of transferred electrons, $z$; and the Faraday constant, $F$. Because activities are related to ion concentration through activity coefficient, the concentrations of oxidant and reductant determine the $E$ and vice versa. In solid electrolytes, only lithium ions are mobile to change the concentration; therefore, presence and absence of lithium should be regarded as the reductant and oxidant, respectively. That is, lithium-ion concentration at the interface is governed by the electrode potential, and noble potential of the oxide cathodes will decrease it.
$E^{0}$ in sulfide will be much lower than that in oxides, because lithium ions are much more loosely bonded to the lattice framework in sulfides. Therefore, $a_{\mathrm{Ox}} / a_{\mathrm{Red}}$, which corresponds to concentration of lithium vacancies, should become very large in order to make the $E$ reach the redox potential of the cathode and start the charge reaction. In other word, the oxidation current in the beginning of charging is spent to remove lithium ions from the sulfide solid electrolyte side of the cathode/sulfide electrolyte interface to increase the $a_{\mathrm{OX}} / a_{\text {Red }}$ in equation (1) before $E$ reaches the redox potential. After the $E$ becomes equal to the redox potential of the cathode, lithium deintercalation from the cathode material begins.

This classical picture may be rough but seems reasonable. The preferential removal of lithium ions from the sulfide electrolyte side can be seen as potential slopes appearing for the uncoated materials in Figure 2, which are distinguishable from the following potential plateaus originated from lithium deintercalation from the cathode materials. Moreover, because $E$ determines the lithium-ion concentrations on the electrode surface in equation (1), the potential slopes should have the same capacity between the $\mathrm{LiCoO}_{2}$ and $\mathrm{LiMn}_{2} \mathrm{O}_{4}$ due to the same electrode potential of $4 \mathrm{~V}$, which is also evidenced by the top panels in Figure 2 . 


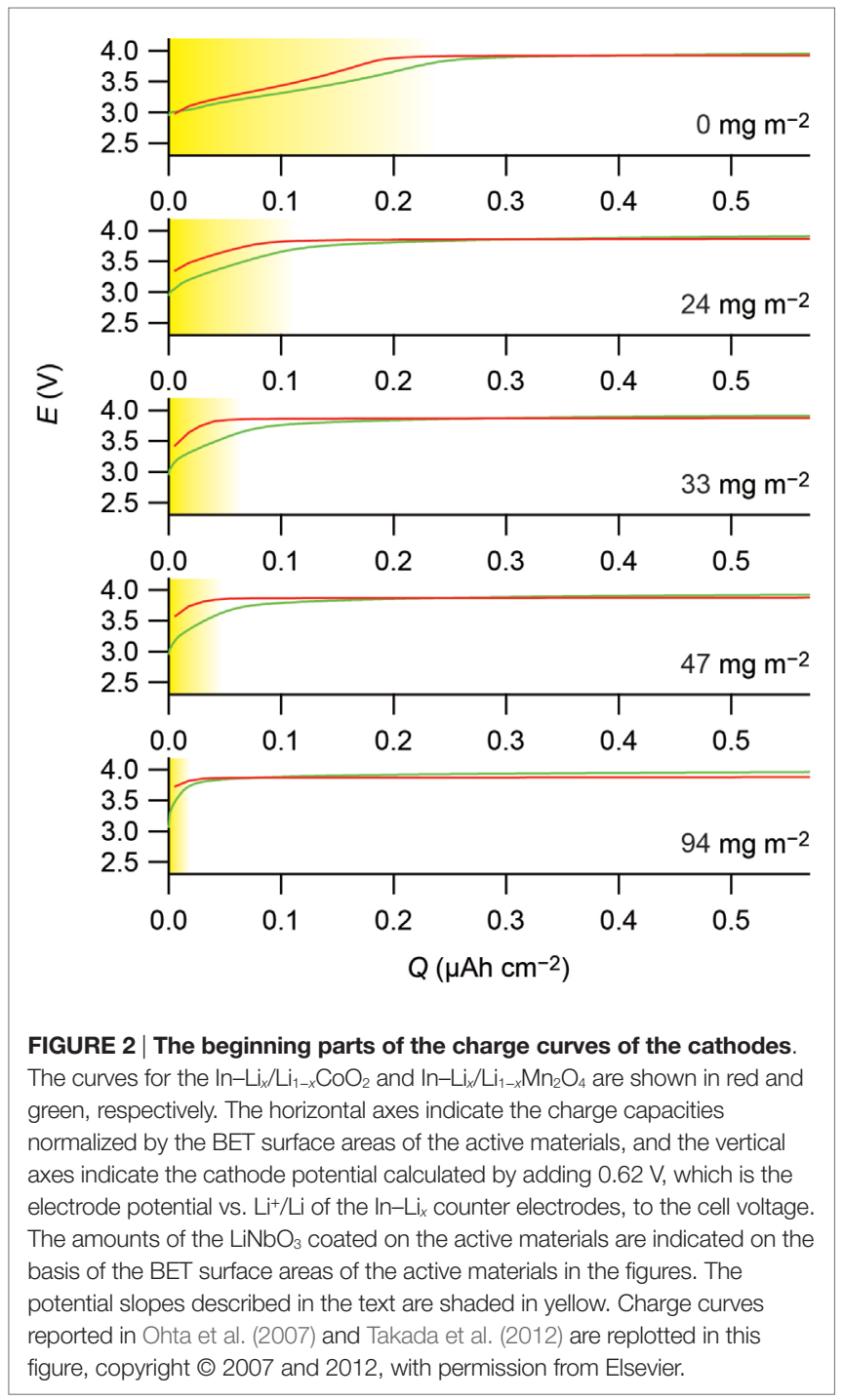

In addition, equation (1) suggests that change in the electrode potential changes lithium-ion concentration exponentially; that is, increasing $E$ results in the drastic decrease of lithium ions. A buffer layer in the first report on the reduced interfacial resistance (Ohta et al., 2006) is $\mathrm{Li}_{4} \mathrm{Ti}_{5} \mathrm{O}_{12}$. Although it decreases the interfacial resistance at $\mathrm{Li}_{1-x} \mathrm{CoO}_{2} / \mathrm{Li}_{3.25} \mathrm{Ge}_{0.25} \mathrm{P}_{0.75} \mathrm{~S}_{4}$ by $1 / 20$, its ionic conductivity is only $10^{-13}-10^{-10} \mathrm{~S} \mathrm{~cm}^{-1}$ (Wilkening et al., 2007; Fehr et al., 2010), while ionic conductivity of the sulfide electrolyte, $\mathrm{Li}_{3.25} \mathrm{Ge}_{0.25} \mathrm{P}_{0.75} \mathrm{~S}_{4}$, is as high as $2.2 \times 10^{-3} \mathrm{~S} \mathrm{~cm}^{-1}$ (Kanno and Murayama, 2001). A reasonable explanation for the reduced resistance inferred from the Nernst equation is that the high bulk conductivity of $\mathrm{Li}_{3.25} \mathrm{Ge}_{0.25} \mathrm{P}_{0.75} \mathrm{~S}_{4}$ becomes so low at the interface due to the exponential decrease in the carrier concentration that even the $\mathrm{Li}_{4} \mathrm{Ti}_{5} \mathrm{O}_{12}$ with low ionic conductivity reduces the resistance.

The DFT calculation results shown in Figure 3 gives a clear explanation for the preferential removal of lithium ions from the $\mathrm{Li}_{3} \mathrm{PS}_{4}$ side upon charging. Charge reaction in $\mathrm{LiFePO}_{4}$ is lithium deintercalation accompanied by the extraction of electrons in $3 d$ orbitals of $\mathrm{LiFePO}_{4}$ located around $-3.5 \mathrm{~V}$. On the other hand,

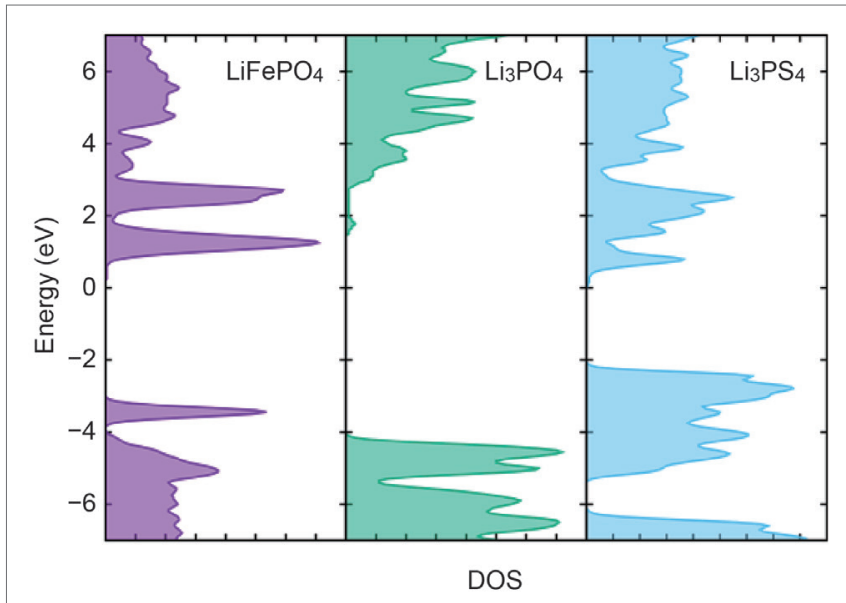

FIGURE 3 | Density of states calculated for $\mathrm{LiFePO}_{4}, \mathrm{Li}_{3} \mathrm{PO}_{4}$, and $\mathbf{L i}_{3} P_{S_{4}}$. Zero in energy is set to the Fermi level of $\mathrm{Li}$ metal.

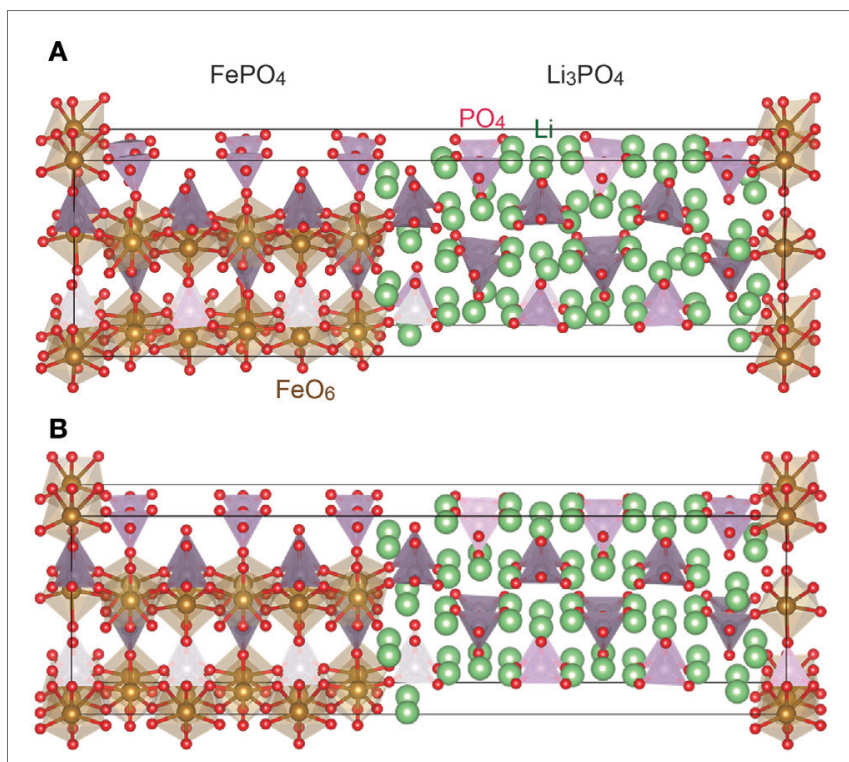

FIGURE 4 | Interface structure between $\mathrm{FePO}_{4}$ and $\mathrm{Li}_{3} \mathrm{PO}_{4}$ before (A) and after (B) the FP-MD. The crystal structures are drawn by a computer program, VESTA (Momma and Izumi, 2011).

$\mathrm{VBM}$ of the $\mathrm{Li}_{3} \mathrm{PS}_{4}$ is located at $-2.0 \mathrm{eV}$, which is higher than the $3 d$ orbital of $\mathrm{LiFePO}_{4}$. Therefore, electrons will be extracted not from the $\mathrm{LiFePO}_{4}$ but from the $\mathrm{Li}_{3} \mathrm{PS}_{4}$ at the beginning of the charge reaction, and simultaneously lithium ions will be extracted from the $\mathrm{Li}_{3} \mathrm{PS}_{4}$ to keep charge neutrality.

\subsection{Reduction of Interfacial Resistance by Surface Coating}

High interfacial resistance at oxide cathodes/sulfide electrolytes is considered to come from lithium-depleted layer formed at the interface, as discussed above. Therefore, reduction of the interfacial resistance by interposing oxide electrolytes observed in the 


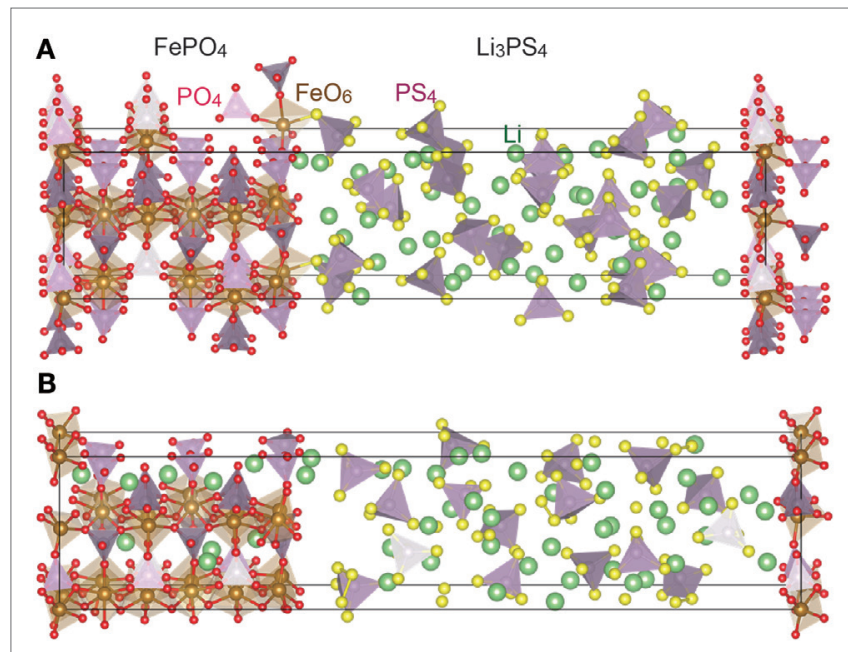

FIGURE 5 | Interface structure between $\mathrm{FePO}_{4}$ and $\mathrm{Li}_{3} \mathrm{PS}_{4}$ before (A) and after (B) the FP-MD. The crystal structures are drawn by a computer program, VESTA (Momma and Izumi, 2011).

experiment should be attributed to the suppression of lithium depletion; that is, lithium-depleted layer is not formed at oxide cathode/oxide solid electrolyte interfaces.

In fact, the FP-MD to relax the interfacial structure does not change distribution of lithium ions around the $\mathrm{FePO}_{4} / \mathrm{Li}_{3} \mathrm{PO}_{4}$ interface, as demonstrated in Figure 4. The $\mathrm{Li}_{3} \mathrm{PO}_{4}$ keeps its original structure at the interface to the $\mathrm{FePO}_{4}$, and lithium depletion is not recognized there. Moreover, the DOS's calculated for $\mathrm{LiFePO}_{4}$ and $\mathrm{Li}_{3} \mathrm{PO}_{4}$ indicate that lithium ions are not preferentially removed from the solid electrolyte. $\mathrm{VBM}$ of the $\mathrm{Li}_{3} \mathrm{PO}_{4}$ is located above $3 d$ orbital of $\mathrm{LiFePO}_{4}$ as shown in Figure 3, and thus charging current should be electrons removed from $\mathrm{LiFePO}_{4}$ even at the beginning. That is, lithium deintercalation from the $\mathrm{LiFePO}$ takes place at the interface to $\mathrm{Li}_{3} \mathrm{PO}_{4}$ from the beginning of charging.

Because lithium ions are not preferentially removed from the oxide electrolyte side of the interface, cathode/oxide electrolyte interfaces do not provide a potential slope to the charging curves. In fact, Figure 2 indicates fading of the potential slopes for the $\mathrm{LiCoO}_{2}$ and $\mathrm{LiMn}_{2} \mathrm{O}_{4}$ observed in the $\mathrm{Li}_{3.25} \mathrm{Ge}_{0.25} \mathrm{P}_{0.75} \mathrm{~S}_{4}$ interfaces upon the $\mathrm{LiNbO}_{3}$ coating. The increasing amount of $\mathrm{LiNbO}_{3}$ coated on the cathode materials gradually shortens the potential slope, which is attributable to the increasing coverage by the coating layer. It decreases the interface area, where the cathode materials are directly contacted to the sulfide solid electrolyte, to eliminate the potential slope. Simultaneously, it increases the cathode/oxide electrolyte interface area, where lithium-depleted layer is not formed, to decrease the interfacial resistance.

The above discussions have revealed that the high interfacial resistance and the effects of surface coating on the electrode properties are explainable by the space-charge model. On the other hand, Sakuda et al. (2010) has proposed another mechanism for the interfacial resistance and its reduction. It reports that transition metals and anions, as well as lithium ions, diffuse across a $\mathrm{Li}_{1-x} \mathrm{CoO}_{2} / \mathrm{Li}_{2} \mathrm{~S}-\mathrm{P}_{2} \mathrm{~S}_{5}$ to form an impurity phase. The impurity phase is concluded to be the reason for the high interfacial resistance, and the surface coating suppresses the mutual diffusion and reduces the interfacial resistance. On the other hand, such mutual diffusion is not observed in the present computations. Figure 5B exhibits that the structure relaxation changes the lithium-ion distribution around the interface without changing the flamework structure. However, it is premature to deny the mutual diffusion, because the relaxation time in the FP-MD simulations is only 200 ps.

It should be noted that $\mathrm{Li}_{1-x} \mathrm{FePO}_{4}$ is used as the cathode material in the computations instead of $\mathrm{Li}_{1-x} \mathrm{CoO}_{2}$ in the experiments in this study. $\mathrm{LiFePO}_{4}$ forms a coherent interface to $\mathrm{Li}_{3} \mathrm{PO}_{4}$, as reported in Sumita et al. (2015). In addition, the surface spin-state of $\mathrm{LiCoO}_{2}$ is complicated, although the manifold spin-states may not affect the band alignment at the interface significantly (Sumita and Ohno, 2016). That is, $\mathrm{Li}_{1-x} \mathrm{FePO}_{4}$ is better than $\mathrm{Li}_{1-x} \mathrm{CoO}_{2}$ to eliminate ambiguities in the computation models, and thus is used in this study. Although computations using $\mathrm{Li}_{1-x} \mathrm{CoO}_{2}$ is preferable to provide an accurate picture on the interfacial phenomena observed in the experiments, coincidences in the electrode properties between the $\mathrm{LiCoO}_{2}$ and $\mathrm{LiMn}_{2} \mathrm{O}_{4}$ in the $\mathrm{Li}_{3.25} \mathrm{Ge}_{0.25} \mathrm{P}_{0.75} \mathrm{~S}_{4}$ and the effects of the surface coating to the interfaces, which are displayed in Figures $\mathbf{1}$ and 2, and the above discussions strongly suggest that electrode potential of cathode materials dominates the lithium-ion concentration at the interface and the interfacial resistance. Of course, electrode potential of $\mathrm{Li}_{1-x} \mathrm{FePO}_{4}$ is $3.5 \mathrm{~V}$ and lower than $4.0 \mathrm{~V}$ for $\mathrm{Li}_{1-x} \mathrm{CoO}_{2}$ to a certain extent; however, both of them are far enough from the VBM of $\mathrm{Li}_{3} \mathrm{PS}_{4}$ not to give significant differences. Therefore, the picture given from the $\mathrm{Li}_{1-x} \mathrm{FePO}_{4}$ will be valid also for the interface to $\mathrm{Li}_{1-x} \mathrm{CoO}_{2}$. Computations on $\mathrm{Li}_{1-x} \mathrm{CoO}_{2}$ are in progress, and the results will appear in near future.

However, some differences may be found between the interfaces to $\mathrm{Li}_{1-x} \mathrm{FePO}_{4}$ and $\mathrm{Li}_{1-x} \mathrm{CoO}_{2}$. These cathode materials are quite different in the electronic conduction: $\mathrm{Li}_{1-x} \mathrm{CoO}_{2}$ exhibits metallic conduction, while $\mathrm{Li}_{1-x} \mathrm{FePO}_{4}$ is poor in electronic conduction and moreover insulating at $x=0$. When they come into contact with a sulfide electrolyte, part of lithium ions in the electrolyte move into the cathode materials, as displayed in Figure 5B. By the way, $\mathrm{Li}_{1-x} \mathrm{FePO}_{4}$ is a two-phase system. Roughly speaking, $\mathrm{Li}_{1-x} \mathrm{FePO}_{4}$ is a mixture of $\mathrm{FePO}_{4}$ and $\mathrm{LiFePO}_{4}$. Therefore, the movement of lithium ions from the electrolyte into the material may form a $\mathrm{LiFePO}_{4}$ layer at the electrode surface. Consequently, $\mathrm{Li}_{1-x} \mathrm{FePO}_{4}$ particles become to have a core-shell structure in sulfide electrolytes, where the core is a mixture of $\mathrm{FePO}_{4}$ and $\mathrm{LiFePO}_{4}$, while the shell mainly consists of $\mathrm{LiFePO}_{4}$. Because the $\mathrm{LiFePO}_{4}$ is electronically insulating, the lithium depletion may be suppressed at the surface of $\mathrm{Li}_{1-x} \mathrm{FePO}_{4}$, and thus the $\mathrm{Li}_{1-x} \mathrm{FePO}_{4}$ may work relatively well even without surface coating in sulfide electrolytes. That is, $\mathrm{Li}_{1-x} \mathrm{FePO}_{4}$ may have a selforiganized core-shell structure for high power, which is similar to that proposed in Xu et al. (2011), where the coating layer is formed only by compositional change in the cathode material.

\section{AUTHOR CONTRIBUTIONS}

$\mathrm{KT}$ and $\mathrm{TO}$ are responsible for the experimental and computational studies, respectively. 


\section{ACKNOWLEDGMENTS}

The authors thank Dr. Narumi Ohta and Dr. Masato Sumita for their collaboration in the experiments and computations, respectively. This work was partially funded by the Ministry

\section{REFERENCES}

Bussi, G., Donadio, D., and Parrinello, M. (2007). Canonical sampling through velocity rescaling. J. Chem. Phys. 126, 014101. doi:10.1063/1.2408420

Fehr, K., Holzapfel, M., Laumann, A., and Schmidbauer, E. (2010). DC and AC conductivity of $\mathrm{Li}_{4 / 3} \mathrm{Ti}_{5 / 3} \mathrm{O}_{4}$ spinel. Solid State Ionics. 181, 1111-1118. doi:10.1016/j. ssi.2010.05.026

Kamaya, N., Homma, K., Yamakawa, Y., Hirayama, M., Kanno, R., Yonemura, M., et al. (2011). A lithium superionic conductor. Nat. Mater. 10, 682-686. doi:10.1038/nmat3066

Kanno, R., and Murayama, M. (2001).Lithium ionic conductor thio-lisicon: the $\mathrm{Li}_{2} \mathrm{~S}-$ $\mathrm{GeS}_{2}-\mathrm{P}_{2} \mathrm{~S}_{5}$ system. J. Electrochem. Soc. 148, A742-A746. doi:10.1149/1.1379028

Maier, J. (1995). Ionic conduction in space charge regions. Prog. Solid State Chem. 23, 171-263. doi:10.1016/0079-6786(95)00004-E

Maier, J. (2014). Pushing nanoionics to the limits: charge carrier chemistry in extremely small systems. Chem. Mater. 26, 348-360. doi:10.1021/ cm4021657

Minami, T., Hayashi, A., and Tatsumisago, M. (2006). Recent progress of glass and glass-ceramics as solid electrolytes for lithium secondary batteries. Solid State Ionics. 177, 2715-2720. doi:10.1016/j.ssi.2006.07.017

Momma, K., and Izumi, F. (2011). VESTA 3 for three-dimensional visualization of crystal, volumetric and morphology data. J. Appl. Crystallogr. 44, 1272-1276. doi:10.1107/S0021889811038970

Ohta, N., Takada, K., Sakaguchi, I., Zhang, L., Ma, R., Fukuda, K., et al. (2007). $\mathrm{LiNbO}_{3}$-coated $\mathrm{LiCoO}_{2}$ as cathode material for all solid-state lithium secondary batteries. Electrochem. commun. 9, 1486-1490. doi:10.1016/j. elecom.2007.02.008

Ohta, N., Takada, K., Zhang, L., Ma, R., Osada, M., and Sasaki, T. (2006). Enhancement of the high-rate capability of solid-state lithium batteries by nanoscale interfacial modification. Adv. Mater. 18, 2226-2229. doi:10.1002/ adma.200502604

Perdew, J. P., Burke, K., and Ernzerhof, M. (1996). Generalized gradient approximation made simple. Phys. Rev. Lett. 77, 3865-3868. doi:10.1103/ PhysRevLett.77.3865

Sakuda, A., Hayashi, A., and Tatsumisago, M. (2010). Interfacial observation between $\mathrm{LiCoO}_{2}$ electrode and $\mathrm{Li}_{2} \mathrm{~S}_{-} \mathrm{P}_{2} \mathrm{~S}_{5}$ solid electrolytes of all-solid state lithium secondary batteries using transmission electron microscopy. Chem. Mater. 22, 949-956. doi:10.1021/cm901819c

Sakuda, A., Hayashi, A., and Tatsumisago, M. (2013). Sulfide solid electrolyte with favorable mechanical property for all-solid state lithium batteries. Sci. Rep. 3, 2261. doi:10.1038/srep02261

Seino, Y., Ota, T., Takada, K., Hayashi, A., and Tatsumisago, M. (2014). A sulphide lithium super ion conductor is superior to liquid ion conductors for use in rechargeable batteries. Energy Environ. Sci. 7, 627-631. doi:10.1039/ C3EE41655K

Sumita, M., and Ohno, T. (2016). Multi-spin-state at $\mathrm{Li}_{3} \mathrm{PO}_{4} / \mathrm{LiCoO}_{2}(104)$ interface. Phys. Chem. Chem. Phys. 18, 4316-4319. doi:10.1039/C5CP07735D of Economy, Trade and Industry (METI), New Energy and Industrial Technology Development Organization (NEDO), ALCA-SPRING project of Japan Science and Technology Agency, and Ministry of Education, Culture, Sports, Science and Technology (MEXT).

Sumita, M., Tanaka, Y., Ikeda, M., and Ohno, T. (2015). Theoretically designed $\mathrm{Li}_{3} \mathrm{PO}_{4}(100) / \mathrm{LiFePO}_{4}(010)$ coherent electrolyte/cathode interface for all solid-state Li ion secondary batteries. J. Phys. Chem. C 119, 14-22. doi:10.1021/ jp5060342

Sumita, M., Tanaka, Y., Ikeda, M., and Ohno, T. (2016). Theoretical insight into charging process in $\mathrm{Li}_{3} \mathrm{PO}_{4}(100) / \mathrm{LiFePO}_{4}(010)$ coherent interface system. Solid State Ionics. 285, 59-65. doi:10.1016/j.ssi.2015.09.029

Takada, K. (2013a). Interfacial nanoarchitectonics for solid-state lithium batteries. Langmuir 29, 7538-7541. doi:10.1021/la3045253

Takada, K. (2013b). Progress and prospective of solid-state lithium batteries. Acta Mater. 61, 759-770. doi:10.1016/j.actamat.2012.10.034

Takada, K., Ohta, N., Zhang, L., Cu, X., Hang, B. T., Ohnishi, T., et al. (2012). Interfacial phenomena in solid-state lithium battery with sulfide solid electrolyte. Solid State Ionics. 225, 594-597. doi:10.1016/j.ssi.2012.01.009

Takada, K., Ohta, N., Zhang, L., Fukuda, K., Sakaguchi, I., Ma, R., et al. (2008). Interfacial modification for high-power solid-state lithium batteries. Solid State Ionics. 179, 1333-1337. doi:10.1016/j.ssi.2008.02.017

Tarascon, J.-M., and Armand, M. (2001). Issues and challenges facing rechargeable lithium batteries. Nature 414, 359-367. doi:10.1038/35104644

Wang, L., Zhou, F., Meng, Y. S., and Ceder, G. (2007). First-principles study of surface properties of $\mathrm{LiFePO}_{4}$ : surface energy, structure, wulff shape, and surface redox potential. Phys. Rev. B 76, 165435. doi:10.1103/PhysRevB.76.165435

Wilkening, M., Amade, R., Iwaniak, W., and Heitjans, P. (2007). Ultraslow Li diffusion in spinel-type structured $\mathrm{Li}_{4} \mathrm{Ti}_{5} \mathrm{O}_{12}$ - a comparison of results from solid state nmr and impedance spectroscopy. Phys. Chem. Chem. Phys. 9, 1239-1246. doi:10.1039/B616269J

Xu, X., Takada, K., Watanabe, K., Sakaguchi, I., Akatsuka, K., Hang, B. T., et al. (2011). Self-organized core-shell structure for high-power electrode in solid-state lithium batteries. Chem. Mater. 23, 3798-3804. doi:10.1021/cm103665w

Zheng, N., Bu, X., and Feng, P. (2003). Synthetic design of crystalline inorganic chalcogenides exhibiting fast-ion conductivity. Nature 426, 428-432. doi: $10.1038 /$ nature02159

Zhu, Y., He, X., and Mo, Y. (2015). Origin of outstanding stability in the lithium solid electrolyte materials: insights from thermodynamic analyses based on first-principles calculations. ACS Appl. Mater. Interfaces 7, 23685-23693. doi:10.1021/acsami.5b07517

Conflict of Interest Statement: The authors declare that the research was conducted in the absence of any commercial or financial relationships that could be construed as a potential conflict of interest.

Copyright (c) 2016 Takada and Ohno. This is an open-access article distributed under the terms of the Creative Commons Attribution License (CC BY). The use, distribution or reproduction in other forums is permitted, provided the original author(s) or licensor are credited and that the original publication in this journal is cited, in accordance with accepted academic practice. No use, distribution or reproduction is permitted which does not comply with these terms. 